\title{
Oleic Acid Produces Motor Incoordination and Hypoactivity in Infant Wistar Rats Through GABA Receptors
}

\author{
Gabriel Guillén-Ruiz ${ }^{1}$, Blandina Bernal-Morales ${ }^{1}$, Carlos M. Contreras ${ }^{1,2, ~ *, ~}$ \\ Jonathan Cueto-Escobedo ${ }^{1}$, Juan Francisco Rodríguez-Landa ${ }^{1}$ \\ ${ }^{1}$ Neuropharmacology Section, Institute of Neuroethology, University of Veracruz, Xalapa, Veracruz, México \\ ${ }^{2}$ Peripheral Unit, Biomedical Research Institute, National Autonomous University of México, Xalapa, Veracruz, México
}

\section{Email address:}

gguillen@uv.mx (G. Guillén-Ruiz), bbernal@uv.mx (B. Bernal-Morales), ccontreras@uv.mx (C. M. Contreras), jcueto@uv.mx (J. Cueto-Escobedo),juarodriguez@uv.mx (J. F. Rodríguez-Landa)

${ }^{*}$ Corresponding author

\section{To cite this article:}

Gabriel Guillén-Ruiz, Blandina Bernal-Morales, Carlos M. Contreras, Jonathan Cueto-Escobedo, Juan Francisco Rodríguez-Landa. Oleic Acid

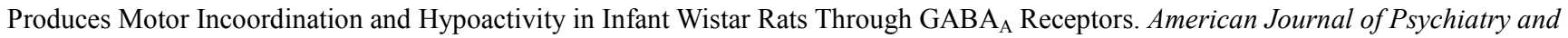
Neuroscience. Vol. 4, No. 2, 2016 pp. 18-25. doi: 10.11648/j.ajpn.20160402.11

Received: March 8, 2016; Accepted: March 18, 2016; Published: March 31, 2016

\begin{abstract}
A mixture of eight fatty acids (linoleic, oleic, palmitic, stearic, myristic, elaidic, lauric, and palmitoleic acids) at similar concentrations that have been identified in human amniotic fluid exerts anxiolytic-like effects similar to diazepam in adult Wistar rats through actions at $\gamma$-aminobutyric acid-A $\left(\mathrm{GABA}_{\mathrm{A}}\right)$ receptors, but unknown is whether any of these fatty acids exerts a predominant action over the others in infant rats. Of these fatty acids, some actions of oleic acid have already been identified, and it is one of the most abundant in amniotic fluid. Therefore, the aim of this study was to explore the effect of oleic acid on anxiety-like behavior and motoric activity in infant rats. To explore sedative actions, 28-day-old Wistar rats received 80-320 $\mu \mathrm{g}$ oleic acid or a sedative dose of diazepam $(5 \mathrm{mg} / \mathrm{kg})$. In a dose-response study, other groups of rats were injected with 10-80 $\mu \mathrm{g}$ oleic acid or $1 \mathrm{mg} / \mathrm{kg}$ diazepam. In an interaction study, rats that received oleic acid were pretreated with the $\mathrm{GABA}_{\mathrm{A}}$ receptor antagonists picrotoxin or flumazenil to explore the participation of this receptor in the effects of oleic acid on behavior in the elevated plus maze, rotarod test, and open field test. Oleic acid produced sedative effects but did not exert any anxiolytic-like actions. Hypoactivity and motor incoordination that were induced by oleic acid were blocked by flumazenil and picrotoxin. In conclusion, oleic acid reduced locomotor activity and motor incoordination through actions at the $\mathrm{GABA}_{\mathrm{A}}$ receptor.
\end{abstract}

Keywords: Hypoactivity, Motor Incoordination, Fatty Acids, Oleic Acid, Anxiety

\section{Introduction}

Amniotic fluid and colostrum are able to promote useful emotional responses in offspring (e.g., orientation and bonding in lambs through individual odors to ensure survival [1] or the odor of rat dams to learn filial huddling preferences [2]). Human newborns who are exposed to scents from their own amniotic fluid exhibit a reduction of crying when the mother is absent [3]. Apparently, these effects are mediated by fatty acids that are contained in human maternal fluids, which are also able to produce appetitive reactions in human newborns [4] and anxiolytic-like actions that are comparable to diazepam in male and female adult Wistar rats $[5,6]$. These effects are blocked by pretreatment with picrotoxin, indicating the participation of $\gamma$-aminobutyric acid-A $\left(\mathrm{GABA}_{\mathrm{A}}\right)$ receptors [7].

$\mathrm{GABA}_{\mathrm{A}}$ receptors can be blocked by antagonists, such as picrotoxin and flumazenil. These antagonists block the anxiolytic, sedative, ataxic, and motor incoordination effects of benzodiazepines and barbiturates [8]. Flumazenil is a selective antagonist of the benzodiazepine allosteric binding site, whereas picrotoxin is a noncompetitive antagonist of $\mathrm{GABA}_{\mathrm{A}}$ receptors that blocks chloride ion channels [8]. Therefore, these antagonists constitute effective tools in the pharmacological screening of drugs that interact with $\mathrm{GABA}_{\mathrm{A}}$ receptors [9].

Oleic acid increases the affinity of flunitrazepam and muscimol, suggesting actions at the benzodiazepine site of 
the $\mathrm{GABA}_{\mathrm{A}}$ receptor $[10,11]$, and modulates the opening of chloride channels [12]. We previously demonstrated that oleic acid is the second most abundant fatty acid in human amniotic fluid, colostrum, and milk [4]. Oleic acid is a monounsaturated fatty acid (C18:1n9) that is widely distributed in nature and the most abundant in such vegetable products as avocados and olives $[13,14]$. This may explain the importance of consumption of the Mediterranean diet (i.e., fruits, vegetables, legumes, and nuts), in which wheat and olive oil are the principal fats [15]. The Mediterranean diet apparently produces beneficial effects that maintain health compared with other diets with a low content of these fatty acids [16]. Epidemiological and preclinical studies have suggested some supposedly protective cardiovascular [17], antiinflammatory [18], antioxidant [16, 19], and antitumor [20] effects of oleic acid, but the results have not been conclusive.

Most preclinical studies have focused on identifying anxiolytic and motor effects by employing adult subjects, but anxiety-related behaviors and pharmacological sensitivity can be age-dependent [21]. Anxiety can be detected at early ages [21, 22], but substances with anxiolytic actions in infant rats have been scarcely explored. Therefore, the present study evaluated the effects of oleic acid on anxiety-like behavior and locomotor activity in infant rats. We also explored the participation of $\mathrm{GABA}_{\mathrm{A}}$ receptors in these actions by using the benzodiazepine stearic receptor blocker flumazenil and $\mathrm{GABA}_{\mathrm{A}}$ receptor chloride channel blocker picrotoxin in infant (postnatal day [PND] 28) Wistar rats.

\section{Materials and Methods}

All of the procedures followed the principles of animal care based on the Guide for the Care and Use of Laboratory Animals [23] and Mexican Official Norm for Care and Use of Lab Animals [24]. The experimental protocol received authorization from the Biomedical Research Institute Ethical Committee, National Autonomous University of Mexico (UNAM).

\subsection{Animals}

The experiments included offspring from Wistar rats, provided by the Biomedical Research Institute, UNAM. During gestation and after delivery, each dam and its litter of $8-10$ pups remained in acrylic boxes $(44 \mathrm{~cm} \times 33 \mathrm{~cm}$ base, 20 $\mathrm{cm}$ height) under a $12 \mathrm{~h} / 12 \mathrm{~h}$ light/dark cycle (lights on at 7:00 AM) with free access to food (Teklad Lab Animal Diets, Harlan, Indianapolis, IN, USA) and purified water. The nest remained undisturbed, and the dams and pups were minimally handled while changing the bedding material (every $48 \mathrm{~h}$ ). The offspring were weaned on PND21 and allocated to six to eight animals per cage ( $44 \mathrm{~cm} \times 33 \mathrm{~cm}$ base, $20 \mathrm{~cm}$ height $)$. On PND28, the offspring were randomly assigned to the experimental groups and immediately underwent behavioral testing. Not more than three offspring from the same litter were assigned to the same experimental group.

\subsection{Experimental Design}

\subsubsection{Sedative Study}

Oleic acid was studied to evaluate its ability to cause sedation. Subcutaneous doses of 80 or $320 \mu \mathrm{g}$ were chosen based on the oleic acid content in $1 \mathrm{ml}$ of amniotic fluid ( 80 $\mu \mathrm{g} / \mathrm{rat})$ as the initial point. Two groups of PND28 rats $(n=6$ per group) were injected with 80 or $320 \mu \mathrm{g}$ oleic acid and compared to a group that was injected with $5 \mathrm{mg} / \mathrm{kg}$ diazepam $(n=6)$ as a sedative reference drug and to a vehicle group $(n=6)$. Two experimental observers evaluated behavior every $5 \mathrm{~min}$ for a total of $120 \mathrm{~min}$ after the injections. The scoring system was on a $0-4$ scale, where $0=$ alert and completely responsive, $1=$ alert but less active and "wobbly," 2 = awake but drowsy with periods of inactivity or mild sedation, 3 = inactive but readily arousable or moderately sedated, and 4 = unresponsive, unconscious, or deeply sedated [25]. Scores were averaged across treatment groups per time point.

\subsubsection{Oleic Acid Dose-Response Study}

To explore any anxiolytic-like and motor effects of oleic acid, the rats were assigned to five experimental groups: $(i) 10$ $\mu \mathrm{g}(n=12)$, (ii) $20 \mu \mathrm{g}(n=15)$, (iii) $40 \mu \mathrm{g}(n=14)$, (iv) $60 \mu \mathrm{g}$ $(n=10)$, and (v) $80 \mu \mathrm{g}(n=10)$, which is equivalent to the amniotic fluid concentration [5]. The data were compared with a vehicle group $(n=10)$ and $1 \mathrm{mg} / \mathrm{kg}$ diazepam group $(n$ $=12$ ) as a reference anxiolytic drug.

\subsubsection{Interaction Between Oleic Acid and $G A B A_{A}$ Receptor Antagonists}

Another four experimental groups were included to identify the mechanism of action of oleic acid. The first group received flumazenil $(5 \mathrm{mg} / \mathrm{kg}, n=9) 30 \mathrm{~min}$ before oleic acid administration $(80 \mu \mathrm{g})$. The second group received picrotoxin $(1 \mathrm{mg} / \mathrm{kg}, n=10) 30 \mathrm{~min}$ before oleic acid administration. These results were compared with an oleic acid group (80 $\mu \mathrm{g}$, $n=10)$ and a vehicle group $(n=10)$. All of the injections were administered subcutaneously in a volume of $1 \mathrm{ml}, 1 \mathrm{~h}$ before the behavioral tests, with the exception of the antagonists in the interaction study that were dissolved in isotonic saline solution and administered intraperitoneally in a volume of 0.5 $\mathrm{ml} 30 \mathrm{~min}$ before the oleic acid injection.

\subsection{Drugs}

Oleic acid was prepared according to previous studies at a concentration similar to that found in human amniotic fluid [5], which produces hypoactivity in adult rats [26]. The preparation consisted of oleic acid $(8 \mathrm{mg})$ dissolved in $100 \mathrm{ml}$ of vehicle ( $96 \%$ propylene glycol and $4 \%$ ethanol) at a temperature $<40^{\circ} \mathrm{C}$. For the sedative study, $32 \mathrm{mg}$ oleic acid was dissolved in $100 \mathrm{ml}$ of vehicle. Oleic acid, flumazenil, and picrotoxin were analytical grade and purchased from Sigma-Aldrich (St. Louis, MO, USA). Propylene glycol and ethanol were obtained from J.T. Baker (Xalostoc, Estado de México, México). Diazepam (Valium 10) was obtained from Hoffman-Roche (Basel, Switzerland). 


\subsection{Behavioral Tests}

The rats were first tested in the elevated plus maze and then in the open field test 5 min later. Five minutes after the open field test, they were tested in the rotarod test.

\subsubsection{Elevated Plus Maze}

The apparatus was constructed of wood and situated in a room with 40 lux illumination. The maze consisted of two opposite open and closed arms set in a plus configuration, elevated $50 \mathrm{~cm}$ from the floor. The open arms $(50 \mathrm{~cm}$ length $\times$ $10 \mathrm{~cm}$ width) were painted white, and the closed arms $(50 \mathrm{~cm}$ length $\times 10 \mathrm{~cm}$ width $\times 40 \mathrm{~cm}$ height) were painted black. The rats were individually placed in the center of the maze, facing an open arm. We recorded the number of entries into and time spent on the open arms for $5 \mathrm{~min}$ [27]. The anxiety index [28] was calculated: $A I=1-[$ [[Open arm time / Test duration] + [Open arm entries / Total number of entries]) / 2]. The total number of entries was the sum of open arm entries plus closed arm entries. At the end of each individual test, the device was cleaned with a $5 \%$ ethanol solution.

\subsubsection{Open Field Test}

After the elevated plus maze test, each rat was placed in a locomotor activity apparatus for $5 \mathrm{~min}$ to evaluate the effects of the treatments on spontaneous locomotor activity. We used an automatic motor activity monitor (Acti-Track v2.7.10, PanLab Instruments, S.L., Barcelona, Spain) constructed of a Perspex box $(45 \mathrm{~cm} \times 45 \mathrm{~cm})$ with $35 \mathrm{~cm}$ high walls that were elevated 3 $\mathrm{cm}$ above the box frame floor. A total of 32 infrared beams, 16 on each perpendicular wall, were mounted on the walls of the box and connected to an interface (LE 8811, LSI Letica Scientific Instruments, Barcelona, Spain) and subsequently to a computer. For data analysis, the floor of the cage was virtually divided into five zones (four peripheral zones and one central zone), and the number of entries into each zone (crossings), total activity time, and total resting time were evaluated for 5 min. No other behaviors, such as rearing or grooming, were evaluated. Because of the relatively small cage dimensions, we did not compare central vs. peripheral exploration.

After each experimental session, the motor activity box was carefully cleaned with a $5 \%$ ethanol solution. Five minutes elapsed between each test to allow the scent of the substances to dissipate.

\subsubsection{Rotarod Test}

To assess the effects of the treatments on motor coordination, all of the rats were trained on the rotarod (LE 8300, LSI Letica, Panlab Scientific Instruments, Barcelona, Spain) for 3 days (PND25, 26, and 27) before the test was conducted on PND28. During the training period, each rat was placed on a horizontal $7-\mathrm{cm}$ diameter rod that rotated at increasing speeds of 4-20 rotations per minute for a maximum period of $5 \mathrm{~min}$ to determine baseline performance. The day of the behavioral test, 5 min after the locomotor activity test, the rats were evaluated in the rotarod test. During the test, the rotarod rotated at the same speed at which the rats were previously trained. The test consisted of five trials with a cutoff time of $3 \mathrm{~min}$. The dependent variable was the total time spent (in seconds) on the rotarod. All of the tests were performed between 11:00 $\mathrm{AM}$ and 3:00 PM.

\subsection{Statistical Analysis}

We used two-way repeated-measures analysis of variance (ANOVA) to analyze data from the sedative study, with treatment and time as factors. Significant effects in the ANOVA were followed by the Holm-Sidak post hoc test. A one-way ANOVA was used to analyze the data from the dose-response study and interactions between the effects of the antagonists and oleic acid. Significant effects in the ANOVA were followed by Dunnett's post hoc test. Values of $p \leq 0.05$ were considered statistically significant. In cases of nonparametric distributions of the data, we used the Kruskal-Wallis and Dunn post hoc tests. The results are expressed as mean $\pm \mathrm{SE}$.

\section{Results}

\subsection{Sedative Study}

The statistical analyses revealed significant effects of treatment $\left(\mathrm{F}_{3,480}=6.722, \mathrm{p}<0.003\right)$ and time $\left(\mathrm{F}_{24,480}=12.029\right.$, $\mathrm{p}<0.001)$ and a treatment $\times$ time interaction $\left(\mathrm{F}_{72,480}=10.968\right.$, $\mathrm{p}<0.001)$. The post hoc test showed that $320 \mu \mathrm{g}$ oleic acid $(1.3 \pm 0.09)$ and $5 \mathrm{mg} / \mathrm{kg}$ diazepam $(1.6 \pm 0.08)$ significantly increased sedation scores compared with the vehicle group $(0.1 \pm 0.04)$. The sedative effect of diazepam was evident 5 min after administration and remained up to $60 \mathrm{~min}$ (Fig. 1A). Oleic acid at $80 \mu \mathrm{g}$ (Fig. 1B) and $320 \mu \mathrm{g}$ (Fig. 1C) produced a longer latency to a sedative effect (i.e., 75 and $80 \mathrm{~min}$ post-injection, respectively) compared with vehicle.
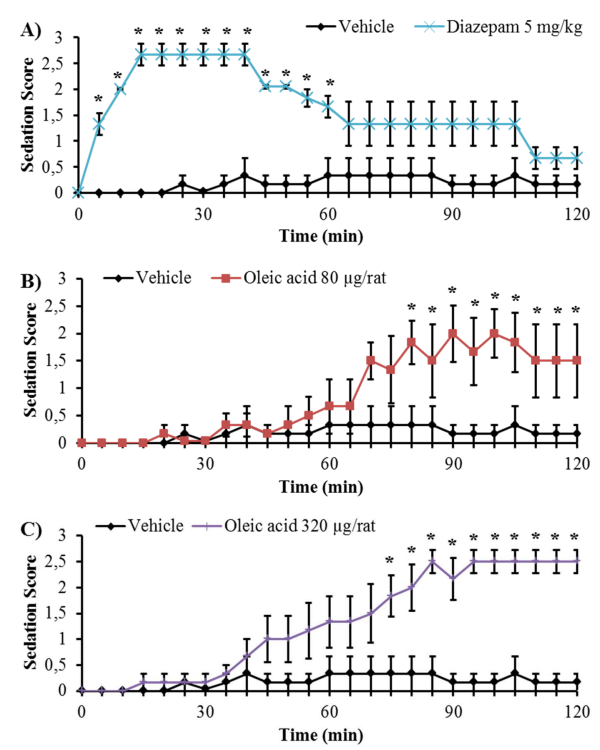

Figure 1. Sedation scores. Diazepam (5 $\mathrm{mg} / \mathrm{kg})$ produced a rapid sedative effect (A). Oleic acid at $80 \mu \mathrm{g}(B)$ and $320 \mu \mathrm{g}(C)$ produced a longer latency to the sedative effect, regardless of the dose. ${ }^{*} p<0.05$, vs. vehicle at the same time of scoring (two-way repeated-measures ANOVA followed by Holm-Sidak post hoc test). 


\subsection{Oleic Acid Dose-Response Study}

\subsubsection{Elevated Plus Maze}

Oleic acid produced similar results as the vehicle group for all of the variables evaluated. As expected, diazepam significantly increased the number of open arm entries $(10.5 \pm$ 1.39) compared with vehicle $\left(3.7 \pm 0.71 ; H_{6}=27.549, p<\right.$ 0.001). None of the effects of oleic acid, regardless of dose, were significantly different from vehicle: $10 \mu \mathrm{g}(3.9 \pm 0.57)$, $20 \mu \mathrm{g}(4.8 \pm 0.92), 40 \mu \mathrm{g}(4.5 \pm 1.05), 60 \mu \mathrm{g}(3.4 \pm 0.96)$, and $80 \mu \mathrm{g}(1.8 \pm 0.51)$.

The statistical analyses revealed differences in the time spent on the open arms $\left(H_{6}=25.314, p<0.001\right)$ and the anxiety index $\left(H_{6}=23.105, p<0.001\right)$. Differences were found between vehicle $(38.8 \pm 9.38 \mathrm{~s})$ and diazepam (112.6 \pm $11.74 \mathrm{~s})$ but not between the different doses of oleic acid $(46.2$ $\pm 9.65 \mathrm{~s}$ for $10 \mu \mathrm{g}, 51.3 \pm 8.64 \mathrm{~s}$ for $20 \mu \mathrm{g}, 42.5 \pm 8.63 \mathrm{~s}$ for 40 $\mu \mathrm{g}, 36.2 \pm 12.41 \mathrm{~s}$ for $60 \mu \mathrm{g}$, and $43.9 \pm 27.69 \mathrm{~s}$ for $80 \mu \mathrm{g}$ ).

Likewise, the anxiety index was similar between vehicle $(0.67 \pm 0.04)$ and $10 \mu \mathrm{g}(0.65 \pm 0.04), 20 \mu \mathrm{g}(0.62 \pm 0.03), 40$ $\mu \mathrm{g}(0.69 \pm 0.04), 60 \mu \mathrm{g}(0.73 \pm 0.06)$ and $80 \mu \mathrm{g}(0.68 \pm 0.13)$ oleic acid but significantly lower $(p<0.05)$ in rats that were treated with diazepam $(0.37 \pm 0.05)$.

\subsubsection{Open Field Test}
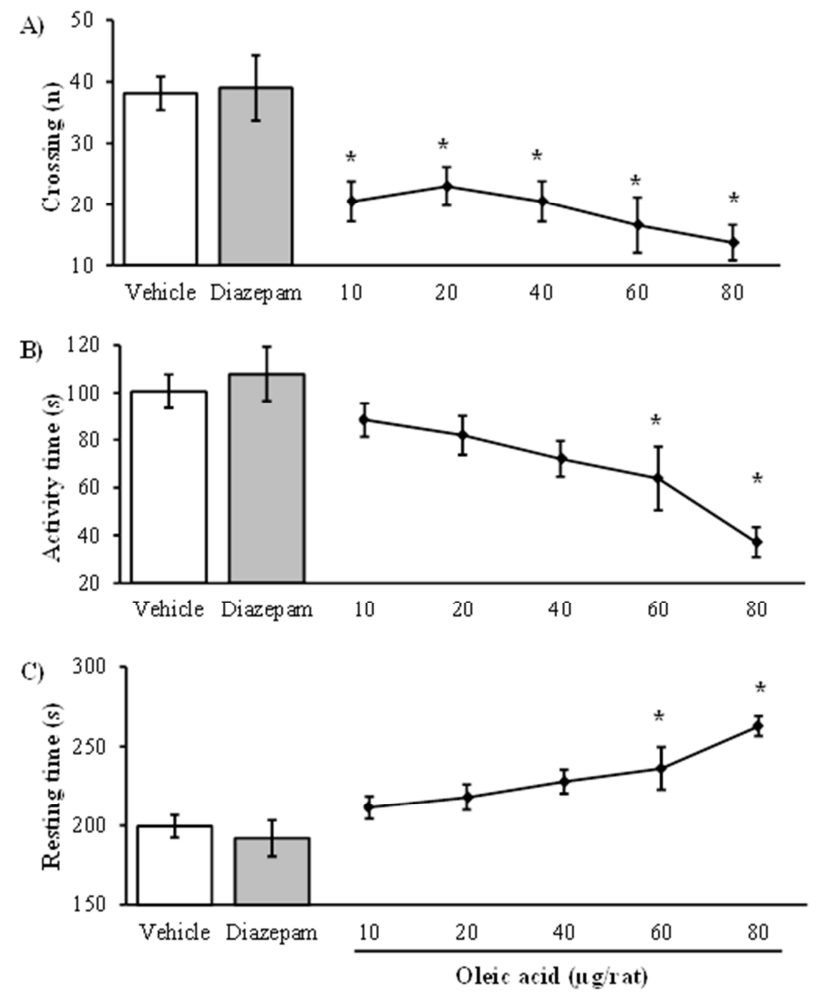

Figure 2. Locomotor activity in PND28 rats treated with oleic acid. Oleic acid decreased the number of crossings (A) and activity time (B) and increased resting time (C). Diazepam did not produce any effects on locomotion. ${ }^{*} p<0.05$, vs. vehicle (one-way ANOVA followed by Dunnett's post hoc test).

Differences in the number of crossings reached statistical significance $\left(F_{6,76}=6.655, p<0.001\right)$. Although no statistically significant dose-response relationship was found, the oleic acid groups presented fewer crossings $(p<0.05)$ compared with the vehicle-treated group (Fig. 2A). Similar results were found with regard to activity time $\left(F_{6,76}=6.338, p\right.$ $<0.001)$ and resting time $\left(F_{6,76}=6.342, p<0.001\right.$; Fig. $\left.2 \mathrm{~B}, \mathrm{C}\right)$. Diazepam did not produce effects in the open field test.

\subsubsection{Rotarod Test}

The treatments dose-dependently affected the total time on the $\operatorname{rotarod}\left(F_{6,76}=18.302, p<0.001\right)$. Oleic acid significantly decreased $(p<0.05)$ the total time on the rotarod (Fig. 3).

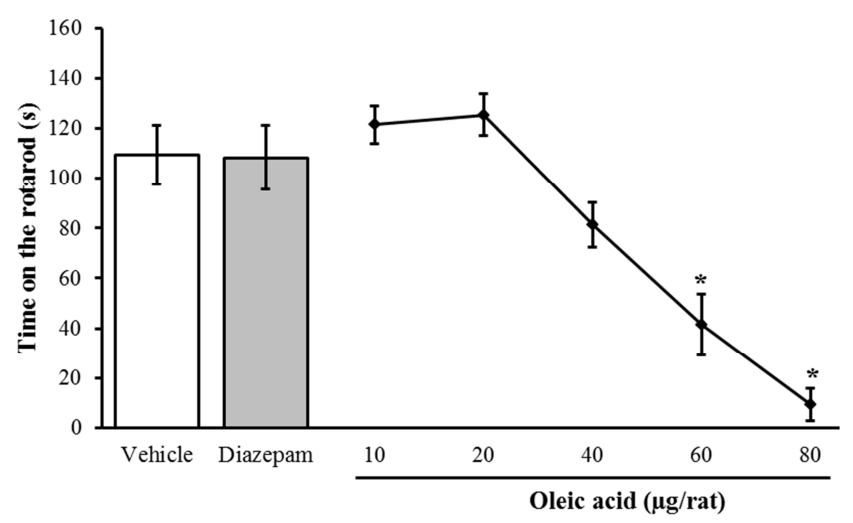

Figure 3. Rotarod results in PND28 rats treated with oleic acid. The total time on the rotarod was lower in the groups that received 60 and $80 \mu \mathrm{g}$ oleic acid compared with the vehicle group. Diazepam did not produce any effects on motor coordination. ${ }^{*} p<0.05$, vs. vehicle (one-way ANOVA followed by Dunnett's post hoc test).

\subsection{Interaction Between Oleic Acid and $G A B A_{A}$ Receptor Antagonists}

\subsubsection{Elevated Plus Maze}

No significant differences were found in the number of open arm entries $\left(F_{3,35}=0.684, p=0.568\right)$ between the flumazenil+oleic acid $(4.2 \pm 0.77)$, picrotoxin+oleic acid (4.3 $\pm 0.81)$, vehicle $(4.7 \pm 0.44)$, and oleic acid $(3.4 \pm 0.58)$ groups. Likewise, no significant differences in the time spent on the open arms were found between the flumazenil+oleic acid $(37.4 \pm 7.08 \mathrm{~s})$, picrotoxin+oleic acid $(37.7 \pm 8.75 \mathrm{~s})$, vehicle $(36.6 \pm 4.92 \mathrm{~s})$, and oleic acid $(39.7 \pm 9.99 \mathrm{~s})$ groups $\left(F_{3,35}=0.0276, p=0.994\right)$. Similar results were found for the anxiety index, with no significant differences between the flumazenil+oleic acid $(0.75 \pm 0.03)$, picrotoxin+oleic acid $(0.78 \pm 0.03)$, vehicle $(0.74 \pm 0.02)$, and oleic acid $(0.72 \pm$ $0.04)$ groups $\left(F_{3,35}=0.476, p=0.701\right)$.

\subsubsection{Open Field Test}

Significant differences in crossings $\left(F_{3,35}=3.297, p<\right.$ $0.032)$, activity time $\left(F_{3,35}=4.671, p<0.008\right)$, and resting time $\left(F_{3,35}=4.674, p<0.008\right)$ were found between the oleic acid and vehicle groups, in which oleic acid increased resting time $(p<0.05)$ and decreased crossings $(p<0.05)$ and activity time $(p<0.05)$ by approximately $50 \%$ compared with the vehicle group. These effects of oleic acid effect were not observed in rats that were pretreated with 
flumazenil and picrotoxin, which were similar to the vehicle group (Fig. 4).
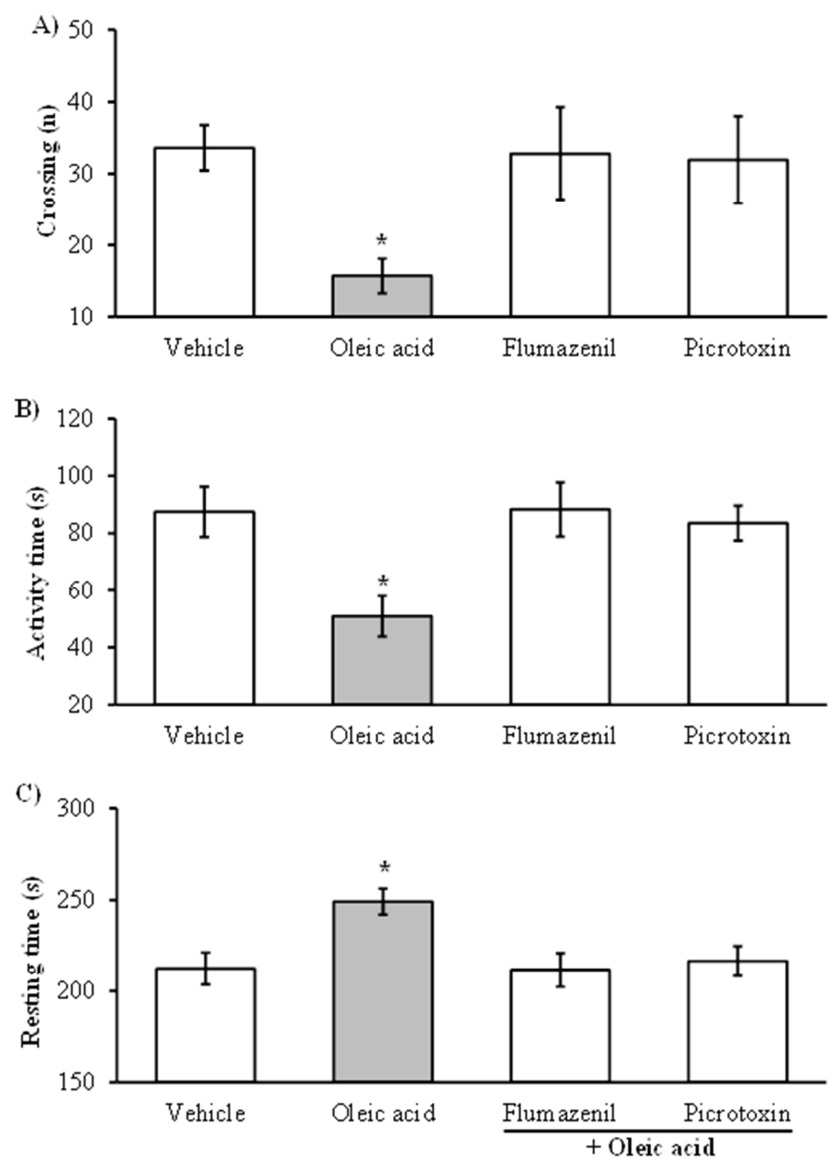

Figure 4. Locomotor activity after $G A B A_{A}$ antagonist administration. The effects of oleic acid on crossings (A), activity time (B), and resting time $(C)$ were blocked by pretreatment with flumazenil and picrotoxin. ${ }^{*} p<0.05$, vs. vehicle (one-way ANOVA followed by Dunnett's post hoc test).

\subsubsection{Rotarod Test}

The total time on the rotarod was significantly affected by treatment $\left(F_{3,35}=10.453, p<0.001\right)$. The oleic acid-induced decrease in the total time spent on the rotarod was not observed in the flumazenil+oleic acid and picrotoxin+oleic acid groups, which were similar to the vehicle group (Fig. 5).

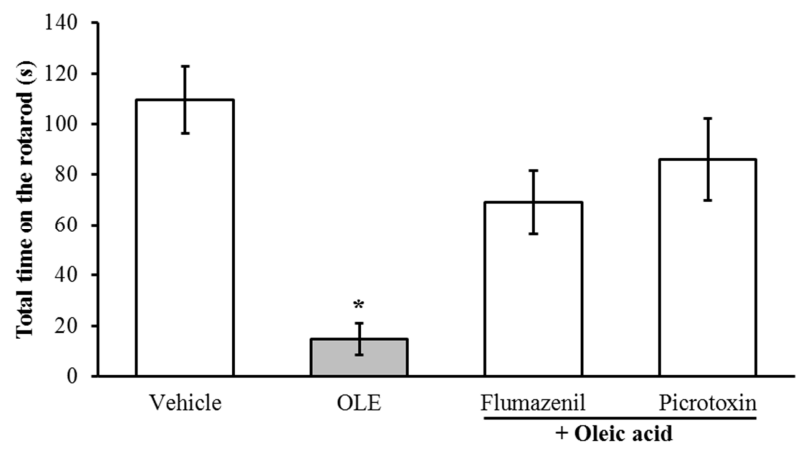

Figure 5. Rotarod performance after $G A B A_{A}$ receptor antagonist administration. The effect of oleic acid was not observed after flumazenil and picrotoxin pretreatment. ${ }^{*} p<0.05$, vs. vehicle (Dunnett's post hoc test).

\section{Discussion}

Anxiety-like behavior can be displayed by young rats [29-31]. Research on anxiety in laboratory animals has important implications for the development of new drugs that come from biological sources, such as maternal fluids. After demonstrating that a fatty acid mixture has anxiolytic-like properties in adult rats [5] and that oleic acid is the second most abundant fatty acid in maternal fluids [4], we evaluated different doses of oleic acid on sedation, anxiety-like behavior, and locomotor activity to possibly identify a natural anxiolytic that may be useful for infants. We found that the minimum effective sedative dose was the same concentration that is found in human amniotic fluid. Oleic acid produced a longer latency to a sedative effect compared with diazepam, which produced rapid sedation. Doses of oleic acid that were up to four times higher than the amount found in human amniotic fluid did not produce different sedative effects. Therefore, the amniotic fluid concentration was selected as the maximum dose for the dose-response study to evaluate the anxiolytic-like effects of oleic acid in infant rats.

The elevated plus maze test is widely used to evaluate anxiolytic and anxiogenic drugs [27, 32]. Typically, "anxious" rats spend a shorter time in the open arms and make fewer open arm entries than control animals [33]. Rats that are administered substances with anxiolytic properties, such as benzodiazepines (e.g., diazepam), display more time on the open arms and make more open arm entries compared with controls. In the present study, diazepam increased the time spent on and number of entries into the open arms three-fold and reduced the anxiety index by approximately $50 \%$ compared with vehicle. Such effects are considered anxiolytic in adult [5, 27, 28] and infant [34] rats. However, in the present study, oleic acid did not produce any anxiolytic-like effects in the elevated plus maze in infant rats, similar to adult rats [26], indicating its null potency as an anxiolytic agent.

An anxiolytic agent at therapeutic doses ideally must produce the expected response without motor alterations. At an appropriate dose, such substances as alcohol, barbiturates, and benzodiazepines produce anxiolysis. Larger doses produce motor incoordination and sedative actions [35]. In the present study, the main effects of 40-80 $\mu \mathrm{g}$ oleic acid consisted of a reduction of locomotor activity and incoordination. Thus, oleic acid appears to have a pharmacological profile that is similar to drugs with myorelaxant actions [35] and partially shares sedative and hypnotic properties with barbiturates [32]. Reductions of locomotor activity may also be caused by other fatty acids, such as palmitic acid [36] or the amide of oleic acid [37-39]. When polyunsaturated fatty acids were added to a rodent diet, $60 \%$ decreases in ambulation, rearing, and exercise time on a running wheel were observed compared with mice that were fed a standard diet [40].

The open field test and rotarod test are two models that present correspondence to different motor activities in rats. In 
the open field test, spontaneous ambulation does not involve learning or conditioning and is useful for discarding possible changes in alertness that could interfere with anxiolytic-like behavior [6]. Rotarod performance implies prior training to display coordination and balance on an accelerating rod. The lack of a dose-response effect in the locomotor activity test suggested a floor effect of oleic acid on spontaneous activity, whereas a clear dose-response effect in the rotarod test suggested that oleic acid alters behaviors that are related to coordination and sedation [41].

The anxiolytic and sedative actions of some drugs occur through chloride ion channel opening [12, 42, 43]. Pentobarbital, an anesthetic drug with actions at $\mathrm{GABA}_{\mathrm{A}}$ receptors, produces ataxia and motor incoordination [41], but its potency as an anxiolytic agent is equivocal [44, 45]. A similar profile was found for oleic acid, which increases the affinity of agonists for the benzodiazepine binding site on $\mathrm{GABA}_{\mathrm{A}}$ receptors [10]. Our data suggest that the hypolocomotor effect of oleic acid is mediated by a direct action on $\mathrm{GABA}_{\mathrm{A}}$ receptors because pretreatment with picrotoxin and flumazenil blocked its effects.

Flumazenil $[8,46]$ and picrotoxin $[47,48]$ do not have intrinsic effects on anxiety-like or locomotor behavior. Therefore, our results suggest that oleic acid has a direct action on the benzodiazepine binding site of $\mathrm{GABA}_{\mathrm{A}}$ receptors. $\mathrm{GABA}_{\mathrm{A}}$ receptors are composed of $\alpha$ subunit variants $(\alpha 1, \alpha 2, \alpha 3$, or $\alpha 5)$ in combination with a $\beta$ subunit $(\beta 1-\beta 2)$ and $\gamma$ subunit [49]. Sedation and anxiolysis are modulated by the $\alpha 1$ and $\alpha 2$ subunits, respectively [50]. Flumazenil is able to completely prevent the action of zolpidem, a benzodiazepine agonist that acts on the $\alpha 1$ subunit, to induce motor/turning behavior [51]. In addition to blocking anxiolytic effects, picrotoxin can also reverse ethanol-induced decreases in the righting reflex in rats [52].

\section{Conclusion}

The present study evaluated the effects of oleic acid that was administered in infant rats on PND28 and explored the participation of $\mathrm{GABA}_{\mathrm{A}}$ receptors in such effects in the elevated plus maze, open field test, and rotarod test. The results showed that oleic acid did not exert any anxiolytic-like actions in the elevated plus maze, but it reduced locomotor activity and motor incoordination apparently through actions at the $\mathrm{GABA}_{\mathrm{A}}$ receptor. In conclusion, oleic acid produced sedative-like effects through $\mathrm{GABA}_{\mathrm{A}}$ receptors without producing anxiolytic-like effects.

\section{Acknowledgements}

The authors thank Michael Arends for revising and editing the English of this manuscript. This study was partially supported by a grant from Programa de Fortalecimiento Académico del Posgrado de Alta Calidad (I010/152/2014C-133/2014) from the University of Veracruz, which did not participate in the study design, data collection, data analysis, interpretation of the data, writing of the manuscript, or decision to submit the paper for publication. J.C.E. and G.G.R. received fellowships from CONACyT (Reg. 197556 and 249708, respectively).

\section{References}

[1] R. Nowak, P. Poindron. "From birth to colostrum: early steps leading to lamb survival". Reprod Nutr Dev, 46(4): 431-446, 2006.

[2] S. Kojima, J. R. Alberts. "Warmth from skin-to-skin contact with mother is essential for the acquisition of filial huddling preference in preweanling rats". Dev Psychobiol, 53: 813-827, 2011.

[3] B. Schaal, L. Marlier. "Maternal and paternal perception of individual odor signatures in human amniotic fluid: potential role in early bonding?" Biol Neonate, 74: 266-273, 1998.

[4] C. M. Contreras, A. G. Gutiérrez-García, R. Mendoza-López, J. F. Rodríguez-Landa, B. Bernal-Morales, C. Díaz-Marte. "Amniotic fluid elicits appetitive responses in human newborns: fatty acids and appetitive responses". Dev Psychobiol, 55(3): 221-231, 2013.

[5] C. M. Contreras, J. F. Rodríguez-Landa, A. G. Gutiérrez-García, M. R. Mendoza-López, R.I. García-Ríos, J. Cueto-Escobedo. "Anxiolytic-like effects of human amniotic fluid and its fatty acids in Wistar rats". Behav Pharmacol, 22(7): 655-662, 2011.

[6] R. I. García-Ríos, J. F. Rodríguez-Landa, C. M. Contreras. "Anxiolytic-like actions of fatty acids identified in human amniotic fluid”. Sci World J, 2013: 823289, 2013.

[7] J. F. Rodríguez-Landa, R. I. García-Ríos, J. Cueto-Escobedo, B. Bernal-Morales, C. M. Contreras. "Participation of $\mathrm{GABA}_{\mathrm{A}}$ chloride channels in the anxiolytic-like effects of a fatty acid mixture". Biomed Res Int, 2013: 121794, 2013.

[8] S. J. Enna. "The GABA receptors". In: The GABA Receptors. S. J. Enna, H. Möhler (ed). Totowa: Humana Press, pp. 1-22, 2007.

[9] G. A. R. Johnston. "GABA A antagonists". Semin Neuroci, 3(3): 205-210, 1991.

[10] M. Nielsen, M. R. Witt, H. Thøgersen. " $\left[{ }^{3} H\right]$ Diazepam specific binding to rat cortex in vitro is enhanced by oleic, arachidonic and docosahexenoic acid isolated from pig brain". Eur J Pharmacol, 146: 349-353, 1988.

[11] J. A. Koenig, I. L. Martin. "Effect of free fatty acids on $\mathrm{GABA}_{\mathrm{A}}$ receptor ligand binding". Biochem Pharmacol, 44(1): 11-15, 1992.

[12] T. C. Hwang, S. E. Guggino, W. B. Guggino. "Direct modulation of secretory chloride channels by arachidonic and other cis unsaturated fatty acids". Proc Natl Acad Sci U S A, 87: 5706-5709, 1990.

[13] F. Takenaga, K. Matsuyama, S. Abe, Y. Torii, S. Itoh. "Lipid and fatty acid composition of mesocarp and seed of avocado fruits harvested at northern range in Japan". J Oleo Sci, 57(11): 591-597, 2008.

[14] M. Fazzari, A. Trostchansky, F. J. Schopfer, S. R. Salvatore, B. Sánchez-Calvo, D. Vitturi, et al. "Olives and olive oil are sources of electrophilic fatty acid nitroalkenes". PLoS One, 9(1): e84884, 2014. 
[15] V. Uylaşer, G. Yildiz. "The historical development and nutritional importance of olive and olive oil constituted an important part of the Mediterranean diet". Crit Rev Food Sci Nutr, 54(8): 1092-1101, 2014.

[16] C. Razquin, J. A. Martínez, M. A. Martínez-González, M. T. Mitjavila, R. Estruch, A. Marti. "A 3 years follow-up of a Mediterranean diet rich in virgin olive oil is associated with high plasma antioxidant capacity and reduced body weight gain”. Eur J Clin Nutr, 63(12): 1387-1393, 2009.

[17] J. Mayneris-Perxachs, A. Sala-Vila, M. Chisaguano, A. I. Castellote, R. Estruch, M. I Covas, et al. "Effects of 1-year intervention with a Mediterranean diet on plasma fatty acid composition and metabolic syndrome in a population at high cardiovascular risk”. PLoS One, 9(3): e85202, 2014.

[18] C. Carrillo, M. M. Cavia, S. Alonso-Torre. "Role of oleic acid in immune system: mechanism of action: a review". Nutr Hosp, 27(4): 978-990, 2012.

[19] R. W. Owen, A. Giacosa, W. E. Hull, R. Haubner, G. Würtele, B. Spiegelhalder, H. Bartsch. "Olive-oil consumption and health: the possible role of antioxidants". Lancet Oncol, 1: 107-112, 2000.

[20] C. Carrillo, M. M. Cavia, S. Alonso-Torre. "Antitumor effect of oleic acid: mechanisms of action: a review". Nutr Hosp, 27(6): 1860-1865, 2012.

[21] C. López-Rubalcava, A. Fernández-Guasti, R. Urba-Holmgren. "Age-dependent differences in the rat's conditioned defensive burying behavior: effect of 5-HT1A compounds". Dev Psychobiol, 29(2):157-169, 1996.

[22] J. A. Vivian, H. M. Barros, A. Manitiu, K. A. Miczek. "Ultrasonic vocalizations in rat pups: modulation at the $\gamma$-aminobutyric acid A receptor complex and the neurosteroid recognition site". J Pharmacol Exp Ther, 282(1): 318-325, 1997.

[23] National Research Council. Guide for the care and use of laboratory animals. Washington DC: National Academy Press, 1985.

[24] NOM-062-ZOO-1999. Especificaciones Técnicas para la Producción, Cuidado y Uso de los Animales de Laboratorio. Secretaría de Agricultura Ganadería Desarrollo Rural, Pesca y Alimentación, 1999.

[25] K. M. Wozniak, J. J. Vornov, B. M. Mistry, Y. Wu, R. Rais, B. S Slusher. "Gastrointestinal delivery of propofol from fospropofol: its bioavailability and activity in rodents and human volunteers". J Transl Med, 13: 170, 2015.

[26] C. M. Contreras, J. F. Rodríguez-Landa, R. I. García-Ríos, J. Cueto-Escobedo, G. Guillén-Ruiz, B. Bernal-Morales. "Myristic acid produces anxiolytic-like effects in Wistar rats in the elevated plus maze". Biomed Res Int, 2014: 492141, 2014.

[27] A. A. Walf, C.A. Frye. "The use of the elevated plus maze as an assay of anxiety-related behavior in rodents". Nat Protoc, 2(2): 322-328, 2007.

[28] H. Cohen, M. A. Matar, J. Zohar. "Animal models of post-traumatic stress disorder". Curr Protoc Neurosci, Chapter 9, Unit 9.45, 2013.

[29] K. Hefner, A. Holmes. "Ontogeny of fear-, anxiety- and depression-related behavior across adolescence in C57BL/6J mice”. Behav Brain Res, 176(2): 210-215, 2007.
[30] D. A. Lynn, G. R. Brown. "The ontogeny of anxiety-like behavior in rats from adolescence to adulthood". Dev Psychobiol, 52(8): 731-739, 2010.

[31] J. Cueto-Escobedo, C. M. Contreras, B. Bernal-Morales, G. Guillén-Ruiz, J. F. Rodríguez-Landa. "Defensive burying test in postweaning rats: utility of a small round chamber". Behav Pharmacol, 24: 693-698, 2013.

[32] S. Pellow, P. Chopin, S. E. File, M. Briley. "Validation of open: closed arm entries in the elevated plus-maze as a measure of anxiety in the rat". J Neurosci Methods, 14: 149-167, 1985.

[33] A. P. Cruz, F. Frei, F. G. Graeff. "Ethopharmacological analysis of rat behavior on the elevated plus-maze". Pharmacol Biochem Behav, 49: 171-176, 1994.

[34] J. T. Imhof, Z. M. Coelho, M. L. Schmitt, G. S. Morato, A. P. Carobrez. "Influence of gender and age on performance of rats in the elevated plus maze apparatus". Behav Brain Res, 56(2): 177-180, 1993.

[35] R. M. McKernan, T. W. Rosahl, D. S. Reynolds, C. Sur, K. A. Wafford, J.R. Atack, et al. "Sedative but not anxiolytic properties of benzodiazepines are mediated by the $\mathrm{GABA}_{\mathrm{A}}$ receptor $\alpha 1$ subtype". Nat Neurosci, 3(6): 587-592, 2000.

[36] M. L. Moon, J. J. Joesting, M .A. Lawson, G. S. Chiu, N. A. Blevins, K. A. Kwakwa, G. G. Freund. "The saturated fatty acid, palmitic acid, induces anxiety-like behavior in mice". Metabolism, 63(9): 1131-1140, 2014.

[37] I. Fedorova, A. Hashimoto, R. A. Fecik, M. P. Hedrick, L. O. Hanus, D. L. Boger, et al. "Behavioral evidence for the interaction of oleamide with multiple neurotransmitter systems". J Pharmacol Exp Ther, 299(1): 332-342, 2001.

[38] M. A. Akanmu, S. O. Odeosum, O. R. Ilesanmi. "Neuropharmacological effects of oleamide in male and female mice”. Behav Brain Res, 182(1): 88-94, 2007.

[39] X. Y. Wei, J. Y. Yang, Y. X. Dong, C. F. Wu. "Anxiolytic-like effects of oleamide in grouped-housed and socially isolated mice". Prog Neuropsychopharmacol Biol Psychiatry, 31(6): 1189-1195, 2007.

[40] B. D. Rockett, M. Harris, S. Raza-Shaikh. "High dose of an n-3 polyunsaturated fatty acid diet lowers activity of C57BL/6 mice". Prostaglandins Leukot Essent Fatty Acids, 86(3): 137-140, 2012.

[41] A. Stinchcomb, B. J. Bowers, J. M. Wehner. "The effects of ethanol and Ro 15-4513 on elevated plus-maze and rotarod performance in long-sleep and short-sleep mice". Alcohol, 6(5): 369-376, 1989.

[42] K. W. Gee, M. B. Bolger, R. E. Brinton, H. Coirini, B. S. McEwen. "Steroid modulation of the chloride ionophore in rat brain: structure-activity requirements, regional dependence and mechanism of action". J Pharmacol Exp Ther, 246: 803-812, 1988.

[43] M. D. Majewska. "Neurosteroids: endogenous bimodal modulators of the $\mathrm{GABA}_{\mathrm{A}}$ receptor: mechanism of action and physiological significance". Prog Neurobiol, 38: 379-395, 1992.

[44] D. Treit, J. P. Pinel, H. C. Fibiger. "Conditioned defensive burying: a new paradigm for the study of anxiolytic agents". Pharmacol Biochem Behav, 15: 619-626, 1981. 
[45] C. Luo, Y. L. Zhang, W. Luo, F. H. Zhou, C. Q. Li, J. M. Xu, R. P. Dai. "Differential effects of general anesthetics on anxiety-like behavior in formalin-induced pain: involvement of ERK activation in the anterior cingulate cortex". Psychopharmacology (Berl), 232(24): 4433-4444, 2015.

[46] A. Fernández-Guasti, O. Picazo. "Flumazenil blocks the anxiolytic action of allopregnanolone". Eur J Pharmacol, 281: 113-115, 1995.

[47] A. Dalvi, R. J. Rodgers. "Anxiolytic effects of valproate and diazepam in mice are differentially sensitive to picrotoxin antagonism". Pharmacol Biochem Behav, 68(1): 23-32, 2001.

[48] P. A. Dombrowski, L. H. Fernandes, R. Andreatini. "Picrotoxin blocks the anxiolytic- and panicolytic-like effects of sodium valproate in the rat elevated T-maze". Eur J Pharmacol, 537(1-3): 72-76, 2006.
[49] J. A. Benson, K. Loëw, R. Keist, H. Mohler, U. Rudolph. "Pharmacology of recombinant $\gamma$-aminobutyric acidA receptors rendered diazepam-insensitive by point-mutated $\alpha$-subunits". FEBS Letters, 431: 400-404, 1998.

[50] H. Möhler. "Functional relevance of $\mathrm{GABA}_{\mathrm{A}}$-receptor subtypes". In: The GABA Receptors. S. J. Enna, H. Möhler (ed). Totowa: Humana Press, pp. 23-40, 2007.

[51] L. Chen, J. X. Xie, K. S. Fung, W. H. Yung. "Zolpidem modulates $\mathrm{GABA}_{\mathrm{A}}$ receptor function in subthalamic nucleus". Neurosci Res, 58(1): 77-85, 2007.

[52] D. B. Beleslin, N. Djokanovic, D. Jovanovic Micic, R. Samardzic. "Opposite effects of $\mathrm{GABA}_{\mathrm{A}}$ and NMDA receptor antagonists on ethanol-induced behavioral sleep in rats". Alcohol, 14(2): 167-173, 1997. 